\title{
AIRWAY MISHAP IN MRI
}

\author{
Pradeep $S^{1}$, Nagaraj A.V ${ }^{2}$
}

${ }^{1}$ Specialist, Department of Anaesthesiology, ESIC Medical College \& PGIMSR.

${ }^{2}$ Specialist, Department of Anaesthesiology, ESIC Medical College \& PGIMSR.

\begin{abstract}
Anaesthetising in Magnetic resonance room poses a challenge to the anaesthesiologist in maintaining the airway without any compromise. Difficulty in ventilation after intubation (Tight bag) is not uncommon. Out of the many causes leading to tight bag situation, we encountered a rare incidence of defective endotracheal tube with pin point opening in the connector.
\end{abstract}

\section{KEYWORDS}

Magnetic Resonance Imaging (MRI), Airway, Tight Bag.

HOW TO CITE THIS ARTICLE: Pradeep S, Nagaraj AV. Airway mishap in MRI. J. Evolution Med. Dent. Sci. 2016;5(34):1957-1958, DOI: $10.14260 /$ jemds/2016/462

\section{INTRODUCTION}

MRI scanning room is a sophisticated environment where the intense magnetic field create unique problems with the usage of standard anaesthesia machines, syringe pumps and monitors (Electrocardiogram, pulse oximetry, capnograph and non-invasive blood pressure). For best quality imaging, the patient should be completely immobilized during scanning which may take around minimum $30 \mathrm{~min}$. In addition, there is a high level of noise in the MRI room.

\section{CASE REPORT}

A 2-year, 6-month-old girl child weighing $12 \mathrm{kgs}$ with history of Cytomegalovirus infection with left eye opacity (CMV ophthalmitis) with Microcephaly was referred for MRI Brain and orbit from a local hospital. Case was planned for MRI under IV sedation after NPO status as per guidelines. Equipment for difficult airway was kept ready. All monitors (ECG, Pulse-oximetry, Capnogram) were attached. Patient was pre-medicated in preparation room with nasal spray Midazolam 2 mg. $^{1}$ and after $10 \mathrm{~min}$. IV line secured. Inj. Glycopyrrolate $0.05 \mathrm{mg}$ IV given. Shifted to MRI room, 024 $\mathrm{ltr} / \mathrm{min}$. connected with face mask. Inj. Ketamine $10 \mathrm{mg}$ IV given as supplemental sedation. Stable capnogram was established before proceeding for scan; $10 \mathrm{~min}$. after the start of scanning $\mathrm{SpO}_{2}$ started dropping from $99 \%$ to $86 \%$ followed by decrease in heart rate to $100 / \mathrm{min}$ from $160 / \mathrm{min}$. Immediately intervened and MRI scan was stopped. Resuscitation was initiated and intubated with 4 no. ET tube orally. CPR was continued as per PALS guidelines. Meanwhile, bilateral air entry checked and absent. Reservoir bag was too tight on ventilation. Heart rate dropped to $45 / \mathrm{min}$. with $\mathrm{SpO}_{2}$ maintained at $50 \%$. Tube position was again reconfirmed by senior anaesthetist and the tube was replaced by another 4 no. ET tube with good chest expansion on ventilation and bilateral air entry confirmed and tube was fixed. Immediately, general condition improved with heart rate 140/min.

Financial or Other, Competing Interest: None

Submission 09-03-2016, Peer Review 05-04-2016,

Acceptance 11-04-2016, Published 28-04-2016.

Corresponding Author:

Dr. Pradeep $S$,

Specialist, Department of Anaesthesiology,

ESIC Medical College \& PGIMSR,

Rajajinagar,

Bengaluru.

E-mail: drpradeepsprasad@gmail.com

DOI: 10.14260/jemds/2016/462
$\mathrm{SpO}_{2}$ 97\% along with spontaneous efforts. Patient was shifted to PICU for monitoring. Child got extubated and discharged on the next day without any neurological deficits.
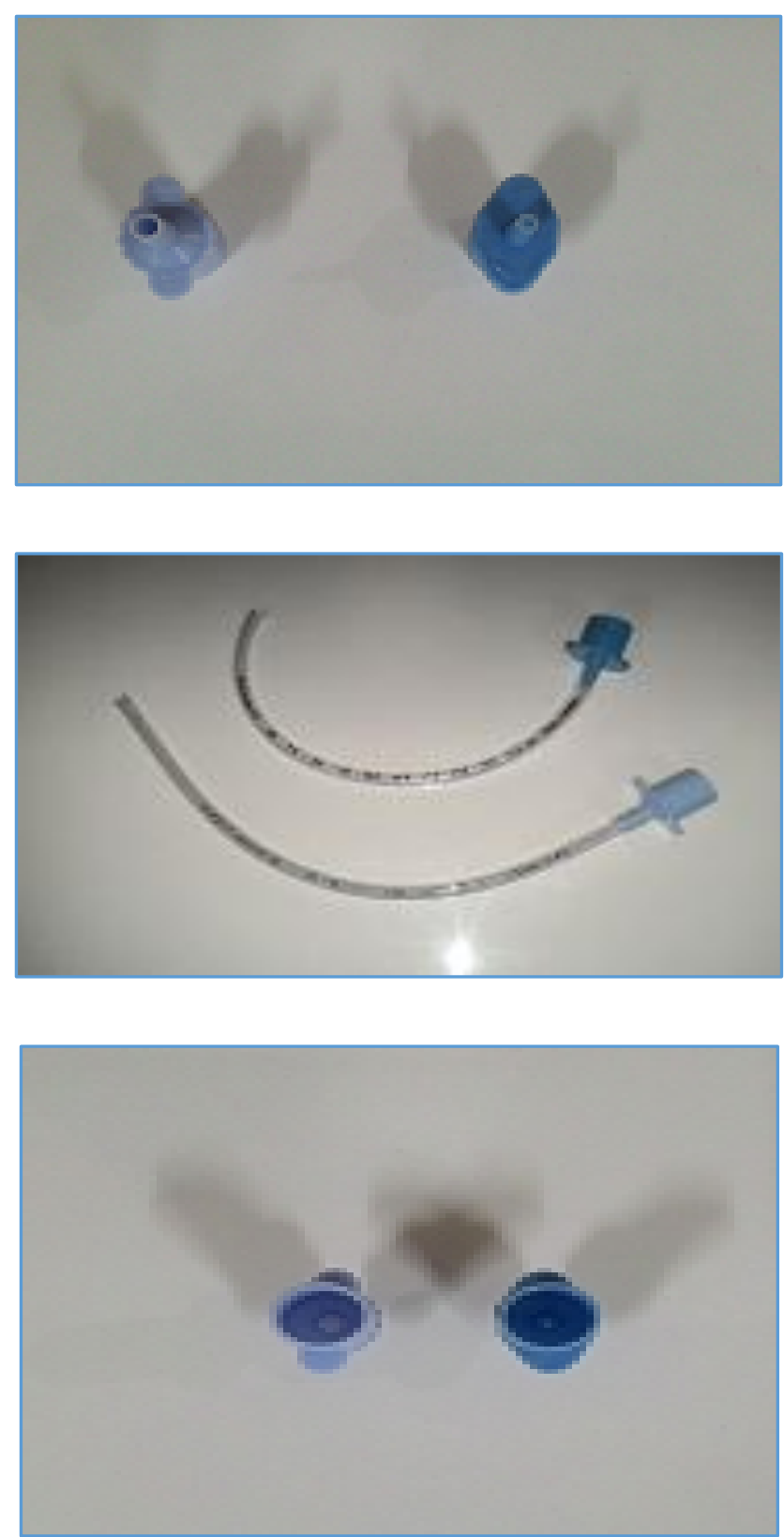

Fig. 1, 2, 3: Connector with Pinpoint Hole at Tube End 


\section{DISCUSSION}

MRI scanning is a relatively non-invasive procedure. It requires complete immobilization of the patient for minimum of 30 to $60 \mathrm{~min}$. That too in presence of loud noise in an enclosed space. This is relatively stressful even for a healthy individual.

The difficulty in ventilation after intubation is not very uncommon situation. The most common cause for this "tight bag" is bronchospasm.

Tight bag is a clinical situation where excessive pressure needs to be applied to a reservoir bag to intubated patient, which may not produce satisfactory ventilation. ${ }^{2}$

\section{Causes of Tight Bag on Ventilation \\ Mechanical (Unanticipated)}

- Twisting of bag at the neck.

- High flows, 02 flush. $^{3}$

- Obstruction in tube. ${ }^{4}$

- Obstruction in circuits. ${ }^{4}$

- Smaller tube.

- Malfunctioning valves.

- $\quad$ Foreign bodies, eg. Tooth, Dentures.

\section{Pathological}

- Hyperreactive airway.

- Bronchial asthma, COPD, Smoker.

- Anaphylaxis.

- Minor Anaphylaxis - Airway oedema.

- Major Anaphylaxis - Hypotension and bronchospasm.

- Aspiration. 4

- Ascites.

- Endobronchial intubation. ${ }^{5}$

- Light anaesthesia.

- Extrinsic compression from tumour.

- Pleural effusion and Pneumothorax (Compression of lung).6,7

- Obesity.
In our case we could not find any of the following causes, but it was a defective ET tube with pinpoint hole at inner diameter of connector (Patient side). This caused the resistance leading to tight bag. Some of the other rare causes reported are the herniation of the cuff occluding the ET tube opening, dissection of the inner layer of the reinforced tube.

\section{CONCLUSION}

Airway mishaps are the commonest to encounter in general anaesthesia, contributing to morbidity and mortality in a setup like MRI. Mechanical causes should be always enclosed before attributing to other causes. In the present anaesthetic practice of 'single use' disposables, one should not take them for granted as defect free or fault free at manufacture.

\section{REFERENCES}

1. Tschirch FT, Gopfert K, Frohlich JM, et al. Low-dose intra nasal versus oral midawolam for routine body MRI of claustrophobic patients. Eur Radiol 2007;17(6):140310.

2. Parthasarathy, Ravishankar. Tight bag. Indian journal of Anaesthesia 2010;54(3):193-8.

3. Brockwell RC, Andrews JJ. Understanding your anaesthesia machine. ASA Refresher Courses in Anaesthesiology 2002;30(1):41-59.

4. John Hoyt. Analyyic reviews: aspiration pneumonitis: patient risk factors, prevention, and management. J Intensive Care Med 1990;5(1):S2-S9.

5. Sprung J, Bourke DL, Harrison C, et al. Endotracheal tube and tracheobronchial obstruction as causes of hypoventilation with high inspiratory pressures. Chest 1994;105(2):550-2.

6. Denlinger JK. Pneumothorax. Complications in anaesthesiology. In: Gravenstein N, Kirby R, editors. Philadaphia pa: Lippincott-Raven publishers, 1996; $2^{\text {nd }}$ ed:241-9.

7. Morgan MD, Edwards CW, Morris J, et al. Origin and behaviour of emphysematous bullae. Thorax 1989;44(7):533-8. 